\title{
Multivariate Dynamic Co-integration and Causality Analysis between Inflation and its Determinants
}

\author{
Md. Sharif Hossain ${ }^{1 *}$, Md. Thasinul Abedin² \\ ${ }^{1}$ University of Dhaka, Dhaka, Bangladesh \\ ${ }^{2}$ International Leasing and Financial Services Limited, Dhaka, Bangladesh \\ *sharif_hossain@du.ac.bd, thasinduais16@gmail.com
}

\begin{abstract}
This paper investigates the impacts of money supply, government expenditure, velocity, industry value addition and economic growth on inflation of Bangladesh using time series data from 1978-2014. The ADF test results suggest that the variables are of I(1). It is found that there exist five co-integration equations. The outcome of the Granger Causality test suggests the short-run unidirectional causality running from industrial value addition to money supply, from inflation, money supply, velocity, industrial value addition and economic growth to government spending. Bidirectional causality has been found between economic growth and industrial value addition. Finally, short-run and long-run effects of money supply, government spending, velocity, industry value addition and economic growth on inflation are estimated. It is found that the speed of adjustment for short-run to approach to the long-run equilibrium level is significant at any significance level. It has been found that it will take about 1.25 years for a complete convergence process to approach its equilibrium. Therefore, in case of any shock to the inflation equation, the speed of adjustment is significantly faster. It has also been found that the long-run effects of money supply and velocity have positive significant effects while the economic growth has significant negative effect on inflation in Bangladesh economy. It has been found that the long-run effects of money supply and velocity are more than short-run effects meaning that over the time more money supply and velocity increase the more and more inflation in Bangladesh but economic growth decreases the inflation.
\end{abstract}

Keywords: ADF Test, Co-integration, Bound Test, Granger Causality, Short-Run and Long-Run Effects, Money Supply, Government Spending, Velocity, Industry Value Addition, and Bangladesh Economy

\section{Introduction}

Attaining sustainable economic growth is a key purpose of every country of emerging economy. Bangladesh despite having a steady economic growth rate over a long tenure is still struggling to maintain that growth level and increase it in the long run. A major problem to keep steady economic growth rate is that many factors either separately or collectively affect economic growth. Inflation rate and economic growth rate is the dominant subject of macroeconomic policy in any country apart from money supply growth, velocity growth, government expenditure growth, and industry value addition growth. Over the long-time period, it has been a debatable issue that actually what type of relationship exists between inflation rate and economic growth rate including the causality relationship between inflation and economic growth. The predicting power of inflation rate for economic growth rate and vice versa has been controversial also. The rate of inflation is affected by the money supply growth rate, velocity growth rate, government expenditure growth rate, and industry value addition growth rate. Over time increases in money supply causes increases in the prices, in other words, the inflation, by increasing expenditures (consumption, government, and investment). It is also notable that velocity growth rate causes inflation rate to go up. The argument between government expenditure growth rate and inflation rate is still continuing. The argument had placed on whether or not the growing public expenditure has the likelihood to persuade inflation. Some researchers are of the acceptance that swelling public expenditure boosts inflation; others are of the view that inflationary force causes the growth rate of government expenditures (Ezirim, Muoghalu and Elike, 2008).

Another area of interest might be to investigate the relationship between inflation rate and industry value addition growth rate. Like economic growth rate it is apparently assumed that industry value addition growth rate is negatively related with the inflation rate. To figure out the relationship between inflation and economic growth, different studies have found the mixed results(Sidrauski (1967), Fischer (1993) and 
Mallick and Chowdhury (2001), Barro (1997)).Thus considering the inflationary rate in Bangladesh economy, this raises to an important question on the effectiveness of money supply on inflation including other important macro-economic variables namely: government expenditure, velocity, industry value addition and economic growth both in short-run and long-run. Therefore, to find the answer of this type of question, this paper investigates the cointegrating and causal relationships between money supply, government spending, velocity, industry value addition, economic growth and inflation. In this paper, another attempt has been made to find the long-run and short-run determinants of inflation in Bangladesh economy using time serried data from 1978-2014. All the variables are expressed in growth rate except inflation. This paper surely helps the policy makers to formulate appropriate and effective economic policies for decision making. The paper is organized as follows: Section II presents a review of empirical literature, Section III discusses the data sources and some descriptive statistics, Section IV discusses econometric methodology with their findings, and Section $V$ discusses concluding remarks and policy implications.

\section{Literature Review}

A bulk of empirical studies has been conducted at the relation between inflation and its determinants. Most empirical studies provide mixed evidence of effectiveness of the determinants of inflation. As for example, Sidrauski (1967) has found no relationship between inflation and economic growth, Fisher (1993) has found negative relationship between inflation and economic growth, and Mallick and Chowdhury (2001) have found positive relationship between inflation and economic growth. It is also found that inflation is the determinant of economic growth (Barro, 1997). Wang (2008) has depicted that economic growth positively relates to inflation with above three quarters' lag. Mohammad et al. (2009) have revealed that in the long run public expenditure and inflation are negatively associated with economic growth while broad money positively affects economic growth. Patra and Sahu (2012) have found that there is adverse relation between inflation and variations in money supply in Bangladesh, Nepal and Pakistan but favorable relation in Nepal and Sri Lanka. Bozkurt (2014) investigated the relationship among money, inflation and growth in Turkey by using co-integration test. Based on the findings, money supply and velocity of money is a main determinant of inflation in the long run in Turkey.

Two key debatable issues are the causality relationship between inflation and economic growth including other determinants of inflation and the predicting power of inflation for economic growth rate and vice versa. Regarding causality analysis between inflation and economic growth including other determinants of inflation a large number of empirical studies have been conducted also the results are very mixed. See for example Paul, Kearney and Chowdhury (1997) have found no causality relationship between inflation and economic growth in $40 \%$ of the countries; bidirectional causality in about $20 \%$ of countries and a unidirectional (either inflation to economic growth or vice versa) relationship in the rest of the countries. Gokal and Hanif (2004) have drawn that granger causality runs one way from growth to inflation but not from inflation to growth meaning that it is unidirectional. Mubarik (2005) has investigated the causal relationship between inflation and economic growth where the test result has suggested that the causality runs from inflation to economic growth but not vice versa. Erbaykal and Okuyan (2008) have scrutinized the causal relationship between inflation and economic growth in the framework of the causality test and their findings have denoted that there is no causal relationship from economic growth to inflation where as there is a causality relationship from inflation to economic growth. Datta and Mukhopadhyay (2011) have found that causality remains between inflation and economic growth in the short run and direction of causality is from inflation to economic growth but in the long run economic growth causes inflation. Ayo et al. (2012) have examined the causal association between economic growth, government expenditures, and inflation rate in Nigeria over the period 1970 to 2010. They have found the existence of bi-directional causal relationship between government expenditures and economic growth both in the short run and in the long run as well. It was also exposed that in the short run the Granger Causality runs from economic growth and government expenditure to inflation rate while no response from inflation rate was perceived. Ojarikre and Ezie (2015) have found not statistically noticeable relation between government expenditure growth and inflation in Nigeria.

The existing literatures expose that as a result of the application of different econometric methodologies and different sample sizes the empirical results are very mixed and even vary for the same country and same 
panel and are not conclusive to present policy formulation that can be applied over the countries. Thus, this study tries to overcome the shortcoming of literatures related with the linkages between inflation and money supply including other determinants of inflation namely: economic growth, velocity, industry value addition, and government expenditure using time series data from 1978-2014 in Bangladesh economy. Also, this empirical study will be important to formulate policy recommendation from the point of view of inflation, money supply, government spending, velocity, economic growth in Bangladesh economy. We believe that this study will be a decent participation into literatures with respect to Bangladesh economy by using the Vector Error Correction Model (VECM). Therefore, the main purpose is to examine the co-integration and causality analysis between money supply, government spending, velocity, industry value addition, economic growth and inflation. Another important attempt has also been made to estimate the long-run and short-run effects of money supply, government spending, velocity, industry value addition, and economic growth on inflation using modern econometric techniques.

\section{Methodology}

This study uses annual time series data from 1978-2014of Bangladesh in order to investigate the cointegration and causality relationships between money supply, government spending, velocity, industry value addition, economic growth and inflation and also to find the long-run and short-run effects of money supply, government spending, velocity, industry value addition, and economic growth on inflation using modern econometric techniques. The variables in the model are money supply growth rate (MSGR), government spending growth rate (GEXGR), velocity growth rate (VEGR), industry value addition growth rate (INVGR), GDP growth rate (GDPGR), and inflation rate (INFR). ${ }^{1}$ For simplicity, money supply is the amount of money circulating in the economy at a definite period of time, government expenditure is the general government final consumption expenditure and expressed as percentage of nominal GDP, velocity is the ratio between nominal GDP and money supply at a time period, the value added of an industry usually referred to GDP of the industry is the contribution of a private industry or government sector to total GDP. It encapsulates employee compensation, taxes on production and imports less subsidies, and gross operating surplus. It is also referred as the simple differential (change) between an industry's aggregate output and the cost of its inbetween inputs, and by inflation we mean a sustainable increase in price level. In the Keynesian sense, true inflation begins when the elasticity of supply of output in response to rise in money supply dropped to zero or when output is not responsive to alteration in money supply. The data sources are UNCTAD Statistics and Word Bank development indicator. Some descriptive statistics namely: mean, standard deviation (Std. Dev.) coefficient of variation (CV), range, skewness and kurtosis of these variables are given below in Table (1).

Table 1: Descriptive Statistics

\begin{tabular}{lllllll}
\hline $\begin{array}{l}\text { Descriptive } \\
\text { Statistics }\end{array}$ & MSGR & GEXGR & VEGR & INVGR & GDPGR & INFR \\
\hline Mean & 17.7625076 & 4.849655 & -3.820266 & 7.0544200 & 4.8800405 & 7.802080 \\
SD & 6.4598163 & 0.533913 & 5.450329 & 3.6236064 & 1.4515471 & 5.165006 \\
CV & 36.3677046 & 11.0092986 & -142.6689 & 51.3664681 & 29.744570 & 66.20037 \\
MIN & 8.2397785 & 4.0306333 & -20.48060 & -5.1736420 & 0.8191419 & 0.1555182 \\
MAX & 42.1755790 & 6.2837686 & 15.05194 & 21.1330198 & 7.2339437 & 25.618885 \\
Range & 33.9358005 & 2.2531353 & 35.53254 & 26.3066618 & 6.4148018 & 25.4633668 \\
Skewness & 1.759006 & 0.493349 & 0.641879 & 0.535497 & -0.616171 & 1.738881 \\
Kurtosis & 4.697213 & 0.596073 & 5.790763 & 8.666050 & 0.511426 & 3.513893 \\
\hline
\end{tabular}

\footnotetext{
1 Inflation Rate $=\left[\frac{\text { Cirrent Year GDP Deflator }}{\text { Previous Year GDP Deflator }}-1\right] \times 100 ;$ GDP Deflator $=\frac{\text { Nominal GDP }}{\text { Real GDP }} \times 100$; Velocity Growth Rate $=\left[\frac{\text { Current Year Velocity }}{\text { Previous Year Velocity }}-1\right] \times 100$ 3

Velocity $=\frac{\text { Nominal GDP }}{\text { Money Supply }}$ Money Supply Growth Rate $=\left[\frac{\text { Cirrent Year Money Supply }}{\text { Previous Year Money Supply }}-1\right] \times 100 ;$ GDP Growth Rate $=\left[\frac{\text { Cirrent Year Real GDP }}{\text { Previous Year Real GDP }}-1\right] \times 100$
} 
From the reported values in Table (1), it is found that the variability is highest for the variable velocity growth rate followed by inflation rate, industrial value addition growth rate, money supply growth rate, economic growth rate and government expenditure growth rate. The results also support that the variables MSGR, GEXGR, VEGR, INVGR and INFR are positively skewed while the variable GDPGR is negatively skewed. The results also support that the curves of the variable MSGR, VEGR, INVAGR and INFR are leptokurtic and the curves of the variables GEXGR and GDPGR are platykurtic.

\section{Results}

The dynamic co-integration and causal relationships between money supply, government spending, velocity, industry value addition, economic growth and inflation are examined using modern econometrics techniques. The long-run impacts of money supply, government expenditure, velocity growth rate, industry value addition rate and economic growth on inflation are examined by estimating the following model:

$$
\mathrm{INFR}_{\mathrm{t}}=\beta_{0}+\beta_{1} \mathrm{MSGR}_{\mathrm{t}}+\beta_{2} \mathrm{GEXGR}_{\mathrm{t}}+\beta_{3} \mathrm{VEGR}_{\mathrm{t}}+\beta_{4} \mathrm{INVGR}_{\mathrm{t}}+\beta_{5} \mathrm{GDPGR}_{\mathrm{t}}+\varepsilon_{\mathrm{t}}(1)
$$

Here, $\beta_{1}, \beta_{2}, \beta_{3}, \beta_{4}$ and $\beta_{5}$ represent the long-run effects of money supply, government expenditure, velocity growth rate, industry value addition and economic growth on inflation.

To investigate, at first we have tested whether each variable contains unit root problem. Next the cointegration relationships between the variables are investigated if unit root problem is found for each variable. The existence of long run relationship supports to investigate the causal relationship between the variables using VEC model. At the final step, the Generalized Method of Moments (GMM) is applied to evaluate the short-run and the long-run relationships between the variables.

Unit Root Tests: If variables under investigation contain stochastic trend, the typical techniques of regression analysis can result in derailed conclusion (Stock and Watson (1988), Granger and Newbold (1974)). More specifically if the dependent variable and no less than one independent variable hold stochastic trend and there is no co-integration between them, the regression results will be counterfeit (Phillips (1986) and Granger and Newbold (1974)). To spot the appropriate specification of the model, an examination of the existence of stochastic trend in the variables is required. To investigate whether each variable contains stochastic trend or not, the ADF test has been applied. The estimation procedure has been outlined below:

$\Delta \mathrm{X}_{\mathrm{t}}=\alpha_{0}+\alpha_{1} \mathrm{t}+\theta \mathrm{X}_{\mathrm{t}-1}+\sum_{\mathrm{i}=1}^{\mathrm{m}} \phi_{\mathrm{i}} \Delta \mathrm{X}_{\mathrm{t}-\mathrm{i}}+\mathrm{u}_{\mathrm{t}}(2)$

Here $\mathrm{X}_{\mathrm{t}}$ is the series under examination, $\Delta$ stands for first difference and the lagged difference terms on the right-hand side of the equations are used to correct auto-correlation problem of disturbance terms. The AIC and SBIC criteria have been used to select the optimal lagged differences. The stochastic variable $\mathrm{X}$ is said to be a I(1) process if $\theta=0$.If it is found that $\mathrm{X}$ is I(1) process then the second order unit root problem needs to be investigated considering the following the following equation:

$\Delta^{2} \mathrm{X}_{\mathrm{t}}=\beta_{0}+\lambda \Delta \mathrm{X}_{\mathrm{t}-1}+\sum_{\mathrm{i}=1}^{\mathrm{m}} \gamma_{\mathrm{i}} \Delta^{2} \mathrm{X}_{\mathrm{t}-\mathrm{i}}+\varepsilon_{\mathrm{t}}(3)$ 
Table 2: ADF Test Results

\begin{tabular}{|c|c|c|c|c|c|c|c|c|}
\hline & \multicolumn{4}{|c|}{ ADF Test [Level Form] Case1 } & \multicolumn{4}{|c|}{ ADF Test [Level Form] Case 2} \\
\hline & Test & Lags & AIC & SBIC & Test & Lags & AIC & SBIC \\
\hline INFR & -2.9329 & 1 & 2.7407 & 2.9166 & $-3.0112^{*}$ & 1 & 2.7011 & 2.8331 \\
\hline MSGR & -3.1169 & 1 & 3.6604 & 3.8826 & $-3.1639 *$ & 1 & 3.5570 & 3.6890 \\
\hline GEXGR & -2.1839 & 3 & -3.4648 & -3.1955 & -2.1800 & 2 & -2.3925 & -2.2147 \\
\hline VEGR & $-3.6794 *$ & 1 & 3.3985 & 3.6207 & $-3.714^{* *}$ & 1 & 3.3354 & 3.4674 \\
\hline INVGR & -3.2116 & 2 & 1.2487 & 1.4709 & -2.49953 & 4 & 1.0487 & 1.3208 \\
\hline \multirow[t]{3}{*}{ GDPGR } & $-4.7421^{* *}$ & 3 & -0.4760 & -0.2066 & -0.35314 & 5 & -0.2047 & 0.1159 \\
\hline & \multicolumn{4}{|c|}{ ADF Test [Differenced Form] Case 1} & \multicolumn{4}{|c|}{ ADF Test [Differenced Form] Case 2} \\
\hline & Test & Lags & AIC & SBIC & Test & Lags & AIC & SBIC \\
\hline$\triangle \mathrm{INFR}$ & $-4.91975^{* *}$ & 1 & 3.0187 & 3.1965 & $-4.892^{* *}$ & 1 & 2.9831 & 3.1164 \\
\hline$\triangle \mathrm{MSGR}$ & $-5.84979 * *$ & 1 & 3.7779 & 3.9557 & $-5.953^{* *}$ & 1 & 3.7219 & 3.8553 \\
\hline$\Delta$ GEXGR & $-5.46669 * *$ & 2 & -3.3610 & -3.1365 & $-5.861^{* *}$ & 2 & -3.4150 & -3.2355 \\
\hline$\Delta$ VEGR & $-5.63967^{* *}$ & 1 & 3.7387 & 3.9164 & $-5.713^{* *}$ & 1 & 3.6853 & -3.8186 \\
\hline$\Delta \mathrm{INVGR}$ & $-10.1045^{* *}$ & 1 & 1.4958 & 1.6736 & $-10.58^{* *}$ & 1 & 1.4395 & 1.5728 \\
\hline$\Delta$ GDPGR & $-5.13295^{* *}$ & 4 & -.2088 & 0.1118 & $-5.195^{* *}$ & 4 & -0.2620 & 0.0128 \\
\hline
\end{tabular}

Case 1: Constant and trend terms are included in the model; Case2: Only Constant term is included in the mode

Here, $\Delta^{2}$ stands as the second-difference operator. $X_{t}$ is referred to be of I (2), If $\lambda=0$. Let, $P$ denotes times that $X_{t}$ requires to be differenced in order to culminate at the stationary level. Thus, $X_{t}$ is referred to be of I(P). As the estimated $\theta$ does not possess the typical asymptotic distribution, the table values given by MacKinnon (1991) are used. These values are more precise than the those of Fuller (1976) and Dickey \& Fuller (1979). The ADF test results are outlined below in Table (2). In differenced form the trend value will be reduced from the equation but here we estimated the equation for both with and without trend value in the differenced form equation. From the test results it can be concluded that all the variables are integrated of order 1.

Test of Co-integration: Bounds test method for co-integration, the Auto-Regressive Distributed lag (ARDL) of Pesaran et al. (2001), has become more widespread. Compared to other single equation co-integration procedure, It possesses certain econometric advantages- (i) relationship between explanatory variables and random error terms and failure to test hypotheses on the projected coefficients in the long-run related to the Engle-Granger approach have been evaded; (ii) long-run and short-run parameters of the model are projected at the same time; (iii) to test the presence of long-run relationship between the variables in level forms, it is suitable even though the time series variables are completely I(0), I(1) or partially integrated; (iv) small sample properties of this method are superior to those of multivariate analysis. To implement the bounds test for co-integration, the following unrestricted regression equations have been constructed:

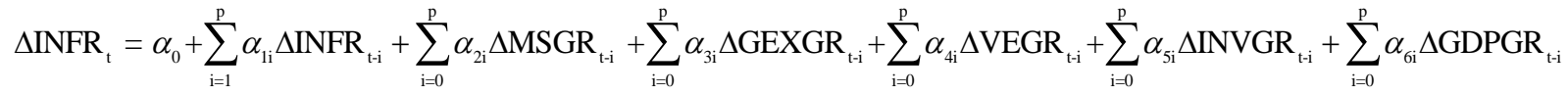

$$
\begin{aligned}
& +\alpha_{7} \mathrm{INFR}_{\mathrm{t}-1}+\alpha_{8} \mathrm{MSGR}_{\mathrm{t}-1}+\alpha_{9} \mathrm{GEXGR}_{\mathrm{t}-1}+\alpha_{10} \mathrm{VEGR}_{\mathrm{t}-1}+\alpha_{11} \mathrm{INVGR}_{\mathrm{t}-1}+\alpha_{12} \mathrm{GDPGR}_{\mathrm{t}-1}+\varepsilon_{1 \mathrm{t}}(4) \\
& \Delta \mathrm{MSGR}_{\mathrm{t}}=\beta_{0}+\sum_{\mathrm{i}=0}^{\mathrm{p}} \beta_{\mathrm{ii}} \Delta \mathrm{INFR}_{\mathrm{t}-\mathrm{i}}+\sum_{\mathrm{i}=1}^{\mathrm{p}} \beta_{2 \mathrm{i}} \Delta \mathrm{MSGR}_{\mathrm{t}-\mathrm{i}}+\sum_{\mathrm{i}=0}^{\mathrm{p}} \beta_{3 \mathrm{i}} \Delta \mathrm{GEXGR}_{\mathrm{t}-\mathrm{i}}+\sum_{\mathrm{i}=0}^{\mathrm{p}} \beta_{4 \mathrm{i}} \Delta \mathrm{VEGR}_{\mathrm{t}-\mathrm{i}}+\sum_{\mathrm{i}=0}^{\mathrm{p}} \beta_{5 \mathrm{i}} \Delta \mathrm{INVGR}_{\mathrm{t}-\mathrm{i}}+\sum_{\mathrm{i}=0}^{\mathrm{p}} \beta_{6 \mathrm{i}} \Delta \mathrm{GDPGR}_{\mathrm{t}-\mathrm{i}} \\
& +\beta_{7} \mathrm{INFR}_{\mathrm{t}-1}+\beta_{8} \mathrm{MSGR}_{\mathrm{t}-1}+\beta_{9} \mathrm{GEXGR}_{\mathrm{t}-1}+\beta_{10} \mathrm{VEGR}_{\mathrm{t}-1}+\beta_{11} \mathrm{INVGR}_{\mathrm{t}-1}+\beta_{12} \mathrm{GDPGR}_{\mathrm{t}-1}+\varepsilon_{2 \mathrm{t}}(5) \\
& \Delta \mathrm{GEXGR}_{\mathrm{t}}=\delta_{0}+\sum_{\mathrm{i}=0}^{\mathrm{p}} \delta_{\mathrm{li}} \Delta \mathrm{INFR}_{\mathrm{t}-\mathrm{i}}+\sum_{\mathrm{i}=0}^{\mathrm{p}} \delta_{2 \mathrm{i}} \Delta \mathrm{MSGR}_{\mathrm{t}-\mathrm{i}}+\sum_{\mathrm{i}=1}^{\mathrm{p}} \delta_{3 \mathrm{i}} \Delta \mathrm{GEXGR}_{\mathrm{t}-\mathrm{i}}+\sum_{\mathrm{i}=0}^{\mathrm{p}} \delta_{4 \mathrm{i}} \Delta \mathrm{VEGR}_{\mathrm{t}-\mathrm{i}}+\sum_{\mathrm{i}=0}^{\mathrm{p}} \delta_{\mathrm{si}} \Delta \mathrm{INVGR}_{\mathrm{ti}}+\sum_{\mathrm{i}=0}^{\mathrm{p}} \delta_{6 \mathrm{i}} \Delta \mathrm{GDPGR}_{\mathrm{t}-\mathrm{i}} \\
& +\delta_{7} \mathrm{INFR}_{\mathrm{t}-1}+\delta_{8} \mathrm{MSGR}_{\mathrm{t}-1}+\delta_{9} \mathrm{GEXGR}_{\mathrm{t}-1}+\delta_{10} \mathrm{VEGR}_{\mathrm{t}-1}+\delta_{11} \mathrm{INVGR}_{\mathrm{t}-1}+\delta_{12} \mathrm{GDPGR}_{\mathrm{t}-1}+\varepsilon_{3 \mathrm{t}}(6) \\
& \Delta \text { VEGR }_{\mathrm{t}}=\theta_{0}+\sum_{\mathrm{i}=0}^{\mathrm{p}} \theta_{\mathrm{li}} \Delta \mathrm{INFR}_{\mathrm{t} \mathrm{i}}+\sum_{\mathrm{i}=0}^{\mathrm{p}} \theta_{2 \mathrm{i}} \Delta \mathrm{MSGR}_{\mathrm{t} \mathrm{i}}+\sum_{\mathrm{i}=0}^{\mathrm{p}} \theta_{3 \mathrm{i}} \Delta \mathrm{GOEXGR}_{\mathrm{ti}}+\sum_{\mathrm{i}=1}^{\mathrm{p}} \theta_{4 \mathrm{i}} \Delta \mathrm{VEGR}_{\mathrm{ti}}+\sum_{\mathrm{i}=0}^{\mathrm{p}} \theta_{5 \mathrm{i}} \Delta \mathrm{INVAGR}_{\mathrm{ti}}+\sum_{\mathrm{i}=0}^{\mathrm{p}} \theta_{6 \mathrm{i}} \Delta \mathrm{GDPGR}_{\mathrm{ti}} \\
& +\theta_{7} \mathrm{INFR}_{\mathrm{t}-1}+\theta_{8} \mathrm{MSGR}_{\mathrm{t}-1}+\theta_{9} \mathrm{GEXGR}_{\mathrm{t}-1}+\theta_{10} \mathrm{VEGR}_{\mathrm{t}-1}+\theta_{11} \mathrm{INVGR}_{\mathrm{t}-1}+\theta_{12} \mathrm{GDPGR}_{\mathrm{t}-1}+\varepsilon_{4 \mathrm{t}}(7)
\end{aligned}
$$




$$
\begin{aligned}
& \Delta \mathrm{INVGR}_{\mathrm{t}}=\gamma_{0}+\sum_{\mathrm{i}=0}^{\mathrm{p}} \gamma_{\mathrm{ii}} \Delta \mathrm{INFR}_{\mathrm{t}-\mathrm{i}}+\sum_{\mathrm{i}=0}^{\mathrm{p}} \gamma_{2 \mathrm{i}} \Delta \mathrm{MSGR}_{\mathrm{t}-\mathrm{i}}+\sum_{\mathrm{i}=0}^{\mathrm{p}} \gamma_{3 \mathrm{i}} \Delta \mathrm{GEXGR}_{\mathrm{t}-\mathrm{i}}+\sum_{\mathrm{i}=0}^{\mathrm{p}} \gamma_{4 \mathrm{i}} \Delta \mathrm{VEGR}_{\mathrm{t}-\mathrm{i}}+\sum_{\mathrm{i}=1}^{\mathrm{p}} \gamma_{5 \mathrm{i}} \Delta \mathrm{INVGR}_{\mathrm{t}-\mathrm{i}}+\sum_{\mathrm{i}=0}^{\mathrm{p}} \gamma_{6 \mathrm{i}} \Delta \mathrm{GDPGR}_{\mathrm{t}-\mathrm{i}} \\
& +\gamma_{7} \mathrm{INFR}_{\mathrm{t}-1}+\gamma_{8} \mathrm{MSGR}_{\mathrm{t}-1}+\gamma_{9} \mathrm{GEXGR}_{\mathrm{t}-1}+\gamma_{10} \mathrm{VEGR}_{\mathrm{t}-1}+\gamma_{11} \mathrm{INVGR}_{\mathrm{t}-1}+\gamma_{12} \mathrm{GDPGR}_{\mathrm{t}-1}+\varepsilon_{5 \mathrm{t}}(8) \\
& \Delta \mathrm{GDPGR}_{\mathrm{t}}=\phi_{0}+\sum_{\mathrm{i}=0}^{\mathrm{p}} \phi_{\mathrm{li}} \Delta \mathrm{INFR}_{\mathrm{t}-\mathrm{i}}+\sum_{\mathrm{i}=0}^{\mathrm{p}} \phi_{2 \mathrm{i}} \Delta \mathrm{MSGR}_{\mathrm{t}-\mathrm{i}}+\sum_{\mathrm{i}=0}^{\mathrm{p}} \phi_{3 \mathrm{i}} \Delta \mathrm{GEXGR}_{\mathrm{t}-\mathrm{i}}+\sum_{\mathrm{i}=0}^{\mathrm{p}} \phi_{4 \mathrm{i}} \Delta \mathrm{VEGR}_{\mathrm{t}-\mathrm{i}}+\sum_{\mathrm{i}=0}^{\mathrm{p}} \phi_{5 \mathrm{i}} \Delta \mathrm{INVGR}_{\mathrm{t}-\mathrm{i}}+\sum_{\mathrm{i}=1}^{\mathrm{p}} \phi_{6 \mathrm{i}} \Delta \mathrm{GDPGR}_{\mathrm{t}-\mathrm{i}} \\
& +\phi_{7} \mathrm{INFR}_{\mathrm{t}-1}+\phi_{8} \mathrm{MSGR}_{\mathrm{t}-1}+\phi_{9} \mathrm{GEXGR}_{\mathrm{t}-1}+\phi_{10} \mathrm{VEGR}_{\mathrm{t}-1}+\phi_{11} \mathrm{INVGR}_{\mathrm{t}-1}+\phi_{12} \mathrm{GDPGR}_{\mathrm{t}-1}+\varepsilon_{6 \mathrm{t}}(9)
\end{aligned}
$$

Pesaran et al. (2001) have suggested that the joint F-test of the lagged level variables in equations (4), (5), (6), (7) (8) and (9) are used to test the existence of long-run equilibrium relationship. In equation (4) the variables are said to be co-integrated if $\mathrm{H}_{0}: \alpha_{7}=\alpha_{8}=\ldots \ldots \ldots . . .=\alpha_{12}=0$ is rejected by using the F-test. The similar procedure would be applied for the remaining equations ((5), (6), (7), (8), (9)) for checking the existence of the long-run equilibrium relationships.

The F-statistic's asymptotic distribution initially derived and tabularized by Pesaran et al. (2001) and modified down the line by Narayan and Russel (2005) to accommodate small sample sizes is not standard under null hypothesis. Between the two sets of critical values- one is suitable given $I(0)$ of all the series and the other is suitable given I(1) of all the series. Pesaran et al. (2001) have suggested a irrefutable inference can be drawn concerning co-integration without getting informed whether the series are I(0) or I(1), if the calculated value of F-statistic falls above the upper critical value. Therefore, the variables are said to be cointegrated hence presence of long-run relationship between the variables. In another way, if the computed Fstatistic lies beneath the lower critical value, co-integration does not exist whether the series are I(0) or I(1). We have to draw inconclusive inference if the calculated F-statistic lies in between lower and upper critical values unless becoming informed whether the series are $\mathrm{I}(0)$ or I(1). The estimated results are outlined below in Table (3):

Table 3: The Results of F-Test for co-integration Relationship

\begin{tabular}{lllll}
\hline Functional Forms & F-test Value & Lags & AIC & SBIC \\
\hline f(INFR|MSGR, GEXGR, VEGR, INVGR, GDPGR) & $4.4267^{*}$ & 1 & -1.5372 & -0.7373 \\
f(MSGR|INFR, GEXGR, VEGR, INVGR, GDPGR) & $14.016^{* *}$ & 1 & -0.9592 & -0.3815 \\
f(GEXGR|INFR, MSGR, VEGR, INVGR, GDPGR) & $8.5080^{* *}$ & 1 & -3.0890 & -2.5113 \\
f(VEGR|INFR, MSGR, GEXGR, INVGR, GDPGR) & $25.333^{* *}$ & 1 & -1.5344 & -0.7345 \\
f(INVGR|INFR, MSGR, GEXGR, VEGR, GDPGR) & $4.8917^{*}$ & 1 & -1.5451 & 1.5338 \\
f(GDPGR & & -0.9675
\end{tabular}

f(GDPGR|INFR, MSGR, GEXGR, VEGR, INVGR)

*Significant at 5\% level, and ${ }^{* *}$ Significant at $1 \%$ level. The critical value ranges of F-statistic are 4.614-5.966, $3.272-4.306$, and $2.676-3.586$ at $1 \%, 5 \%$ and $10 \%$ level of significance respectively. See Narayan and Russel (2005).

From the above results (Table-3), it can be said that there exist five co-integration relationships. The first, second, third, fifth and sixth long-run relationships refer to the situation where INFR, MSGR, GEXGR, INVGR and GDPGR are the dependent variables respectively. The result is inconclusive where VEGR is dependent variable at $5 \%$ level of significance but it is significant at $10 \%$ level.

Granger Causality Test: The results of the co-integration test cannot say the direction of causality between the variables. Therefore, causal relationship between the variables has been investigated by using the Engle and Granger (1987) causality F-test on the first differenced form of variables by including an Error Correction Term (ECM) to capture the long-run relationship. The augmented form of the Granger Causality Test involving the Error Correction Term has been developed in a multivariate $\mathrm{P}^{\text {th }}$ order Vector Error Correction Model which is given below: 


$\left[\begin{array}{c}\Delta \mathrm{INFR}_{\mathrm{t}} \\ \Delta \mathrm{MSGR}_{\mathrm{t}} \\ \Delta \mathrm{GEXGR}_{\mathrm{t}} \\ \Delta \mathrm{VEGR}_{\mathrm{t}} \\ \Delta \mathrm{INVGR}_{\mathrm{t}} \\ \Delta \mathrm{GDPGR}_{\mathrm{t}}\end{array}\right]=\left[\begin{array}{c}\mathrm{C}_{1} \\ \mathrm{C}_{2} \\ \mathrm{C}_{3} \\ \mathrm{C}_{4} \\ \mathrm{C}_{5} \\ \mathrm{C}_{6}\end{array}\right]+\sum_{\mathrm{i}=1}^{\mathrm{p}}\left[\begin{array}{cccccc}\beta_{11 \mathrm{i}} & \beta_{12 \mathrm{i}} & \beta_{13 \mathrm{i}} & \beta_{14 \mathrm{i}} & \beta_{15 \mathrm{i}} & \beta_{16 \mathrm{i}} \\ \beta_{21 \mathrm{i}} & \beta_{22 \mathrm{i}} & \beta_{23 \mathrm{i}} & \beta_{24 \mathrm{i}} & \beta_{25 \mathrm{i}} & \beta_{26 \mathrm{i}} \\ \beta_{31 \mathrm{i}} & \beta_{32 \mathrm{i}} & \beta_{33 \mathrm{i}} & \beta_{34 \mathrm{i}} & \beta_{35 \mathrm{i}} & \beta_{36 \mathrm{i}} \\ \beta_{41 \mathrm{i}} & \beta_{42 \mathrm{i}} & \beta_{43 \mathrm{i}} & \beta_{44 \mathrm{i}} & \beta_{45 \mathrm{i}} & \beta_{46 \mathrm{i}} \\ \beta_{51 \mathrm{i}} & \beta_{52 \mathrm{i}} & \beta_{53 \mathrm{i}} & \beta_{54 \mathrm{i}} & \beta_{55 \mathrm{i}} & \beta_{56 \mathrm{i}} \\ \beta_{61 \mathrm{i}} & \beta_{62 \mathrm{i}} & \beta_{63 \mathrm{i}} & \beta_{64 \mathrm{i}} & \beta_{65 \mathrm{i}} & \beta_{66 \mathrm{i}}\end{array}\right]\left[\begin{array}{c}\Delta \mathrm{INFR}_{\mathrm{t}-\mathrm{i}} \\ \Delta \mathrm{MSGR}_{\mathrm{t}-\mathrm{i}} \\ \Delta \mathrm{GEXGR}_{\mathrm{t}-\mathrm{i}} \\ \Delta \operatorname{VEGR}_{\mathrm{t} \mathrm{i}} \\ \Delta \mathrm{INVGR}_{\mathrm{t}-\mathrm{i}} \\ \Delta \mathrm{GDPGR}_{\mathrm{t} \mathrm{i}}\end{array}\right]+\left[\begin{array}{c}\lambda_{1} \\ \lambda_{2} \\ \lambda_{3} \\ \lambda_{4} \\ \lambda_{5} \\ \lambda_{6}\end{array}\right] \operatorname{ECM}_{\mathrm{t}-1}+\left[\begin{array}{c}\varepsilon_{1 \mathrm{t}} \\ \varepsilon_{2 \mathrm{t}} \\ \varepsilon_{3 \mathrm{t}} \\ \varepsilon_{4 \mathrm{t}} \\ \varepsilon_{5 \mathrm{t}} \\ \varepsilon_{6 \mathrm{t}}\end{array}\right](10)$

In equation (10) the term $\Delta$ denotes first difference, the C's, $\beta$ 's and $\lambda$ 's are the parameters to be projected.

$\mathrm{ECM}_{\mathrm{t}-1}$ represents the one period lagged error-term derived from the co-integration vector and $\varepsilon$ 's are independently and identically distributed with mean zero and constant variance. Each variable is treated as endogenous. Here, to analyze the direction of any causal relationship between the variables, $\mathrm{F}$ test has been applied. In equation (10) the variable money supply does not granger cause the inflation in the short run if all the coefficients- $\beta_{12 i}$ 's $\forall$ i are zero. Similarly, the inflation does not Granger cause money supply in the short run if and only if all the coefficients $\beta_{21 i}$ 's $\forall$ i are not significantly different from zero. The long-run causal relationships between the variables in equation (10) would be studied by testing the significance of the coefficients of ECM's. The short run and long run granger causality test results are reported below in Table (4).

The findings in Table (4) indicates that short-run unidirectional causality running from industrial value addition to money supply, from inflation, money supply, velocity, industrial value addition and economic growth to government spending, Bidirectional causality is found between economic growth and industrial value addition. It has been found that the error correction term is statistically significant at $10 \%$ level when government spending is endogenous variable.

Table 4: Granger F-Test Results

\begin{tabular}{llllllll}
\hline & $\Delta$ INFR & $\Delta$ MSGR & $\Delta$ GEXGR & $\Delta$ VEGR & $\Delta$ INVGR & $\Delta$ GDPGR & ECM \\
\hline$\Delta$ INFR & & 1.3191 & 0.0544 & 0.8181 & 0.7937 & 1.6405 & -0.5391 \\
& & $(0.2608)$ & $(0.8173)$ & $(0.3737)$ & $(0.3808)$ & $(0.2111)$ & $(0.5942)$ \\
$\Delta$ MSGR & 0.2125 & & 0.0050 & 0.1766 & $5.3273^{*}$ & 1.0750 & 0.0734 \\
& $(0.6485)$ & & $(0.9444)$ & $(0.6776)$ & $(0.0289)$ & $(0.3090)$ & $(0.9419)$ \\
$\Delta$ GEXGR & $5.0382^{*}$ & $5.7253^{*}$ & & $4.7819^{*}$ & $13.7792^{*}$ & $6.2264^{*}$ & $-1.7634^{* *}$ \\
& $(0.0332)$ & $(0.0239)$ & & $(0.0376)$ & $(0.0009)$ & $(0.0190)$ & $(0.0891)$ \\
$\Delta$ VEGR & 0.0342 & 0.0464 & 0.0034 & & 1.3773 & 0.0069 & 0.5926 \\
& $(0.8547)$ & $(0.8311)$ & $(0.9539)$ & & $(0.2508)$ & $(0.9344)$ & $(0.5584)$ \\
$\Delta$ INVGR & 1.8062 & 1.6845 & 1.3651 & 1.9269 & & $5.0840^{*}$ & -1.3243 \\
& $(0.1902)$ & $(0.2053)$ & $(0.2529)$ & $(0.1764)$ & & $(0.0324)$ & $(0.1965)$ \\
$\Delta$ GDPGR & 0.7472 & 0.3426 & 1.2144 & 0.6455 & $38.2822^{*}$ & & -0.0402 \\
& $(0.3950)$ & $(0.5632)$ & $(0.2801)$ & $(0.4287)$ & $(0.0000)$ & & $(0.9682)$ \\
\hline
\end{tabular}

The figures in the parenthesis are the p-values. ${ }^{*}$ and $^{* *}$ indicate test statistics that are significant at $5 \%$ and $10 \%$ level respectively.

Short-Run and Long-Run Effects: The following co-integration equation is projected to study the long-run sensitivity between the variables:

$\mathrm{INFR}_{\mathrm{t}}=\delta_{0}+\sum_{\mathrm{i}=1}^{\mathrm{p}} \delta_{\mathrm{li}} \mathrm{INFR}_{\mathrm{t}-\mathrm{i}}+\sum_{\mathrm{i}=0}^{\mathrm{p}} \delta_{2 \mathrm{i}} \mathrm{MSGR}_{\mathrm{t}-\mathrm{i}}+\sum_{\mathrm{i}=0}^{\mathrm{p}} \delta_{3 \mathrm{i}} \mathrm{GEXGR}_{\mathrm{t}-\mathrm{i}}+\sum_{\mathrm{i}=0}^{\mathrm{p}} \delta_{4 \mathrm{i}} \mathrm{VEGR}_{\mathrm{t}-\mathrm{i}}+\sum_{\mathrm{i}=0}^{\mathrm{p}} \delta_{5 \mathrm{i}} \mathrm{INVGR}_{\mathrm{t}-\mathrm{i}}++\sum_{\mathrm{i}=0}^{\mathrm{p}} \delta_{6 \mathrm{i}} \mathrm{GDPGR}_{\mathrm{t}-\mathrm{i}}+\omega_{\mathrm{t}}(11)$

As lag order selection in ARDL model is highly sensitive, the selection has been accomplished by using two criteria- AIC and SBIC. The short run association among the variables can be calculated considering the following error correction model:

$\Delta \mathrm{INFR}_{\mathrm{t}}=\psi_{0}+\sum_{\mathrm{i}=1}^{\mathrm{p}} \psi_{1 \mathrm{i}} \Delta \mathrm{INFR}_{\mathrm{t}-\mathrm{i}}+\sum_{\mathrm{i}=0}^{\mathrm{p}} \psi_{2 \mathrm{i}} \Delta \mathrm{MSGR}_{\mathrm{t}-\mathrm{i}}+\sum_{\mathrm{i}=0}^{\mathrm{p}} \psi_{3 \mathrm{i}} \Delta \mathrm{GEXGR}_{\mathrm{t}-\mathrm{i}}+\sum_{\mathrm{i}=0}^{\mathrm{p}} \psi_{4 \mathrm{i}} \Delta \operatorname{VEGR}_{\mathrm{t}-\mathrm{i}}+\sum_{\mathrm{i}=0}^{\mathrm{p}} \psi_{5 \mathrm{i}} \Delta \mathrm{INVGR}_{\mathrm{t}-\mathrm{i}}$ 


$$
+\sum_{\mathrm{i}=0}^{\mathrm{p}} \psi_{6 \mathrm{i}} \Delta \mathrm{GDPGR}_{\mathrm{t}-\mathrm{i}}+\lambda \mathrm{ECM}_{\mathrm{t}-1}+\mathrm{u}_{\mathrm{t}}
$$

Here, $\mathrm{ECM}_{\mathrm{t}-1}$ is the error correction term which is obtained from the following estimated co-integration equation:

$\mathrm{ECM}_{\mathrm{t}}=\mathrm{INFR}_{\mathrm{t}}-\delta_{0}-\sum_{\mathrm{i}=1}^{\mathrm{p}} \delta_{1 \mathrm{i}} \mathrm{INFR}_{\mathrm{t}-\mathrm{i}}-\sum_{\mathrm{i}=0}^{\mathrm{p}} \delta_{2 \mathrm{i}} \mathrm{MSGR}_{\mathrm{t}-\mathrm{i}}-\sum_{\mathrm{i}=0}^{\mathrm{p}} \delta_{3 \mathrm{i}} \mathrm{GEXGR}_{\mathrm{t}-\mathrm{i}}-\sum_{\mathrm{i}=0}^{\mathrm{p}} \delta_{4 \mathrm{i}} \mathrm{VEGR}_{\mathrm{t}-\mathrm{i}}-\sum_{\mathrm{i}=0}^{\mathrm{p}} \delta_{5 \mathrm{i}} \operatorname{INVAGR}_{\mathrm{t}-\mathrm{i}}-\sum_{\mathrm{i}=0}^{\mathrm{p}} \delta_{6 \mathrm{i}} \mathrm{GDPGR}_{\mathrm{t}-\mathrm{i}}$

Here $\lambda$ denotes the speed of adjustment for short-run to reach in the long-run equilibrium. The estimated long-run and also the short -run effects of money supply, government spending, velocity, industry value addition, and economic growth on inflation are given below in Tables (5) and (6):

Table 5: Long-Run Coefficients

\begin{tabular}{llll}
\hline Dependent Variable INFR & Coefficient & t-Test & Probability \\
\hline Constant & 0.8583 & 0.8592 & 0.3973 \\
MSGR & $0.8254^{*}$ & 31.64723 & 0.0000 \\
GEXGR & 0.2197 & 1.1125 & 0.2751 \\
VEGR & $1.0816^{*}$ & 34.3508 & 0.0000 \\
INVGR & -0.0320 & -0.87721 & 0.3876 \\
GDPGR & $-0.9523^{*}$ & -10.34161 & 0.0000 \\
\hline
\end{tabular}

*Significant at any significance level

From estimated results in Table (6), it has been found that money supply, velocity, and industrial value addition have significant positive effects on inflation while government spending and economic growth have negative effects but the effect of economic growth is statistically significant in the short-run. The error correction mechanism (ECM) is employed to check the short-run relationship among the variables.

The speed of adjustment for short run to reach in the long-run equilibrium is statistically significant which is suggested by the estimated coefficient of ECM $(-1)$. The error correction term -0.80 with the expected sign suggests that whether inflation is above or below its equilibrium level, it adjusts by almost $80 \%$ within the first year. The full convergence process to its equilibrium level takes about1.25 years. Thus, the speed of adjustment is significantly faster in the case of any shock to the inflation equation. From the estimated results in Table (5) it has also been found that in the long-run the variables money supply, government spending, and velocity have positive effects on inflation but the effects of money supply and velocity are statistically significant while the variables industrial value addition and economic growth have negative effects but the effect of the variable economic growth is statistically significant. Since the long-run effects of the variable money supply and velocity are higher than short-run effects meaning that over time higher money supply and velocity will increase more inflation in Bangladesh economy. But in respect of other variables economic growth, and industrial value addition, the inflation will be declined over time.

Table 6: Short-Run Coefficients

\begin{tabular}{llll}
\hline Dependent Variable $\Delta$ INFR & Coefficient & t-Test & Probability \\
\hline Constant & -0.0425 & -0.53331 & 0.5992 \\
$\Delta$ MSGR & $0.7278^{*}$ & 23.9723 & 0.0000 \\
$\Delta$ GEXGR & -0.5883 & 1.5172 & 0.1435 \\
$\Delta$ VEGR & $1.0505^{*}$ & 42.2932 & 0.0000 \\
$\Delta$ INVGR & $0.1213^{*}$ & 2.4032 & 0.0251 \\
$\Delta$ GDPGR & -1.0636 & 8.4883 & 0.0000 \\
ECM $\{-1\}$ & $-0.80086^{*}$ & -3.37518 & 0.0027 \\
Sensitivity Analysis & Diagnostic Test Results & & Probability \\
LM Test for Autocorrelation & 1.6927 & & 0.1932 \\
LM test for Heteroscedasticity & 5.5892 & & 0.3483 \\
ARCH Test & 0.0124 & & 0.9112 \\
JB Test for Normality of Errors & 1.2083 & & 0.5466 \\
\hline
\end{tabular}

*Significant at any significance level 
Sensitivity Analysis: The diagnostic tests results indicate there is no problem of serial correlation, autoregressive conditional heteroscedasticity, and heteroscedasticity. The test results also support that there is no problem of normality of random error terms in equation (12).

CUSUM and CUSUMSQ Tests: The cumulative sum (CUSUM) and cumulative sum of squares (CUSUMSQ) tests suggested by Borensztein et al. (1998) have been used to investigate the stability of the long-run parameters together with the short-run movements for the equations. The associated graphs of these tests are depicted below in Figures 1 and 2:

Figure 1: Plot of Cumulative Sum of Recursive Residuals

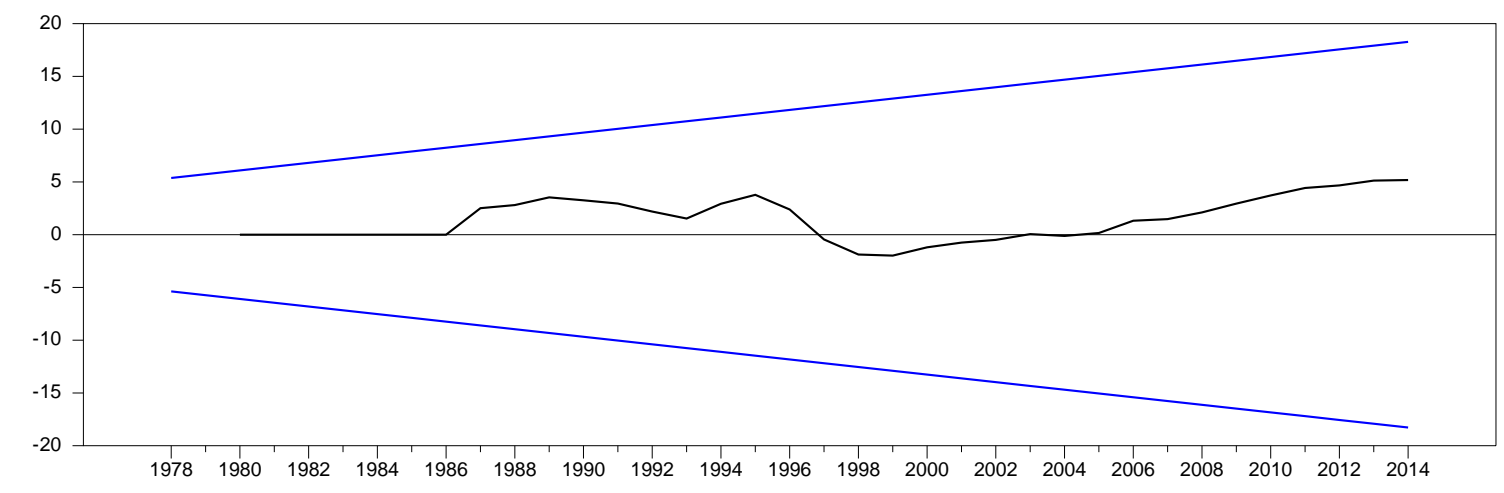

The straight lines represent critical bounds at 5\% significance level

Figure 2: Plot of Cumulative Sum of Squares of Recursive Residuals

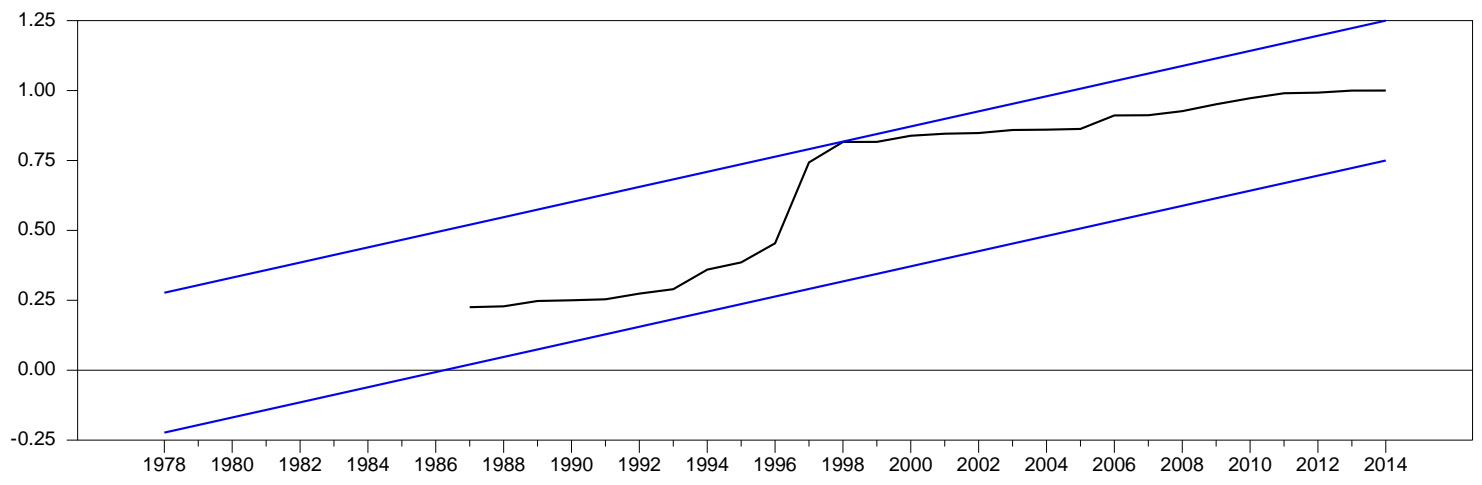

The straight lines represent critical bounds at $5 \%$ significance level.

It has been observed from figures (1) and (2) that all coefficients in the error correction model are stable. Thus, the favored INFR model can be used for formulation of appropriate policies and taking effective decisions so that the effect of policy changes by taking into account the explanatory variables of INFR equation will not cause major alteration in the level of INFR as the parameters in this equation appear to follow a stable pattern during the period of estimation.

\section{Conclusion and Policy Implications}

This paper has tried to investigate empirically the dynamic co-integration and causal relationships between money supply, government expenditure, velocity, industry value addition, economic growth and inflation using time series data from 1978-2014. The investigation procedure involves five steps. At the first step, the ADF test is applied to investigate the unit root problem. The test results support [see Table 2] that the variables money supply, government expenditure, velocity, industry value addition, economic growth and inflation are of I(1). Since all the variables are of I(1), there is a co-integration relationship among the variables. Therefore, at the second step, the Bounds Testing method for co-integration has been used in order 
to examine the presence of long-run equilibrium relationship between inflation and its determinants. The test results support [see Table 3] that there exist five co-integration equations. This implies that the explanatory variables money supply, government expenditure, velocity, industry value addition, and economic growth are merging with inflation to achieve their steady-state equilibrium in the long-run, even though nonconformities may occur in the short-run. The co-integration relationship indicates the existence of causal relationships between variables but it cannot say anything about the direction of causal relationship between variables. To detect the causal relationship between variables, the Engle and Granger test has been applied. Thus, at the third step Granger F-test is applied to VECM to investigate the causal relationships between different pairs of variables. The Granger causality test results support [see Table 4] the short-run unidirectional causality from industrial value addition to money supply, from inflation, money supply, velocity, industrial value addition and economic growth to government spending, Bidirectional causality is found between economic growth and industrial value addition. Finally, short-run and long-run effects of money supply, government spending, velocity, industry value addition and economic growth on inflation are estimated. At the fourth step, GMM is applied to estimate the long-run and short-run effects of money supply, government expenditure, velocity, industry value addition, economic growth on inflation in Bangladesh economy. From estimated results [see Table 6] it has been found that money supply, velocity, and industrial value addition have significant positive effects on inflation while government spending and economic growth have negative effects but the effect of economic growth is statistically significant in the short-run.

The Error Correction Mechanism (ECM) is employed to check the short-run relationship among the variables. The test results suggest that the coefficient of ECM (-1) is statistically significant at $5 \%$ level of significance meaning that speed of adjustment for short-run to reach in the long-run equilibrium is significant. The error correction term is statistically significant and its magnitude is quite higher indicating a faster return to equilibrium in the case of disequilibrium. The error correction term is -0.80 with the expected sign, suggesting that when inflation is above or below its equilibrium level, it adjusts by almost $80 \%$ within the first year. The full convergence process to its equilibrium level takes about 1.25 years. Thus, the speed of adjustment is significantly faster in the case of any shock to the inflation equation. Also from the estimated results [see Table 5] it has also been found that in the long-run the variables money supply, government spending, and velocity have positive effects on inflation but the effects of money supply and velocity are statistically significant while the variables industrial value addition and economic growth have negative effects but the effect of economic growth is statistically significant. Since the long-run effects of money supply and velocity are higher than short-run effects meaning that over time higher money supply and velocity will increase more inflation in Bangladesh economy. But in respect of other variables namely economic growth, and industrial value addition, the inflation will be declined over time. The diagnostic tests results [see Table 6] indicate that there is no evidence of serial correlation, and there is no problem of heteroscedasticity. Also, the autoregressive conditional heteroscedasticity is not present in the short-run model. The test results also support that there is no problem of normality of random error terms in equation (12). The CUSUM and CUSUMSQ tests results suggest that all the coefficients in the error correction model are stable. Therefore, the preferred INFR model can be used for formulation of appropriate policies and proper decision making purposes so that the impact of policy changes considering the explanatory variables of INFR equation will not cause major distortion in the level of INFR, as the parameters in this equation seem to follow a stable pattern during the estimation period. Since it has been found that in the long-run as well as in the short run, the variables money supply and velocity have significant positive effects on inflation also in the long run the variable government spending has positive effect on inflation, therefore it is very essential to apply some sort of mechanisms to control money supply, velocity and government spending which may control the inflation in Bangladesh economy. It has also been found that the variable economic growth has significant negative impact on inflation both in the sort-run and in the long-run. Thus, the government has to formulate policies in favor of the liberal trade policies for FDI, and trade openness, policies for domestic investment, research and development expenditure, to reduce dependency on foreign aid which plays significant role for economic development in Bangladesh as a result inflation will be reduced over time in Bangladesh economy.

\section{References}

Ayo, O. S., Ifeakachukwu, N. P. \& Ditimi, A. (2012). A Tri-variate Causality Test among Economic Growth, Government Expenditure and Inflation Rate: Evidence from Nigeria. Research Journal of Finance and Accounting, 3(1), 65-72. 
Barro, J. R. (1997). Determinants of Economic Growth: A Cross-Country Empirical Study. NBER Working Paper No. 5698, Issued in August 1996, NBER Program(S): EFG, 5698.

Borensztein, E., De Gregorio, J. \& Lee, J. W. (1998). How does FDI affect economic growth. Journal of International Economics, 45(1), 115-135.

Bozkurt, C. (2014). Money, Inflation and Growth Relationship: The Turkish Case. International Journal of Economics and Financial Issues, 4(2), 309-322.

Datta, K. \& Mukhopadhyay, C. K. (2011). Relationship between Inflation and Economic Growth in Malaysia An Econometric Review. International Conference on Economics and Finance Research IPEDR, 4, 415419.

Dickey, D. A. \& Fuller W. A. (1979). Distribution of the Estimators for the Autoregressive Time Series with a Unit Root. Journal of the American Statistical Association, 79, 355-367.

Engle, R. F. \& Granger, C. W. J. (1987). Cointegration and Error Correction: Representation, Estimation and Testing. Econometrica, 55(2), 251-276.

Erbaykal-Sr., E. \& Okuyan, H. (2008). Does Inflation Depress Economic Growth? Evidence from Turkey. International Journal of Finance and Economics, 13(17), 41-47.

Ezirim, C., Muoghalu, M. \& Elike, U. (2008). Inflation versus public expenditure growth in the US: An empirical investigation. North American Journal of Finance and Banking, 2(2), 26-40.

Fischer, S. (1993). The Role of Macroeconomic Factors in Growth. NBER Working Paper, No. 4565.

Fuller, W. A. (1976). Introduction to Statistical Time Series. New York: Wiley

Gokal, V. \& Hanif, S. (2004). Relationship between Inflation and Economic Growth in Fiji. Working Paper 2004/04.

Granger, C. W. J. \& Newbold P. (1974). Spurious Regression in Econometrics. Journal of Econometrics, 2, 111120.

MacKinnon, J. G. (1991). Critical Values for Cointegration Tests. In R. F. Engle and C. W. J. Granger (eds), LongRun Economic Relationships, Reading in Cointegration, Oxford University Press.

Mallik, G. \& Chowdhury, A. (2001). Inflation and Economic Growth: Evidence from South Asian Countries. Asian Pacific Development Journal, 8(1), 123-135

Mohammad, S., Wasti, S., Lal, I. \& Hussain, A. (2009). An Empirical Investigation between Money Supply, Government Expenditure, output \& Prices: The Pakistan Evidence. European Journal of Economics, Finance and Administrative Sciences, 17, 60-68.

Mubarik, Y. A. (2005). Inflation and Growth: An Estimate of the Threshold Level of Inflation in Pakistan. SBPResearch Bulletin, 1(1), 35-43.

Narayan, P. K. \& Russell, S. (2005). Dead Man Walking: an Empirical Reassessment of the Deterrent Effect of Capital Punishment Using the Bounds Testing Approach to Cointegration, Applied Economics._Taylor \& Francis Journals, 38 (17),1975-1989.

Ojarikre, 0. \& Ezie, O. (2015). Public Expenditure Growth and Inflation in Nigeria: The Causality Approach. SSRG International Journal of Economics and Management Studies, 2(1), 26-28

Patra, S. \& Sahu, K. (2012). Inflation in south Asia and its macroeconomic linkages. Journal of Arts, Science \& Commerce, 3(2), 10-15.

Paul, S., Kearney, C. \& Chowdhury, K. (1997). Inflation and Economic Growth: A Multi-Country Empirical Analysis. Applied Economics, 29(10), 1387-1301.

Pesaran, M. H., Shin, Y. \& Smith, R. J. (2001), Bound Testing Approaches to the Analysis of Level Relationships. Journal of Applied Econometrics, 16, 289-326.

Phillips, P. C. B. (1986). Understanding Spurious Regression in Econometrics. Journal of Econometrics, 33, 331-340.

Sidrauski, M. (1967). Rational Choice and Patterns of Growth in a Monetary Economy. American Economic Review, 57(2),534-544.

Stock, J. H. \& M. W. Watson (1988). Testing for common trends. Journal of the American Statistical Association, 83, 1097-1107.

Wahid, A., Shahbaz, M. \& Azim, P. (2011). Inflation and Financial Sector Correlation: The Case of Bangladesh. International Journal of Economics and Financial Issues, 1(4), 1-9.

Wang, Z. (2008). Chinese Economic Growth and Inflation. Chinese society science Institute Press. 